\title{
Warranty Assessment of Photovoltaic Modules based on a Degradation Probabilistic Model
}

\author{
Francisco Prieto-Castrillo (1,2), Neftalí Núñez (3) and Manuel Vázquez (3).
}

1) ETSIS Telecomunicación, Campus Sur, Universidad Politécnica de Madrid. Dpto. Electrónica Física, Ingeniería Eléctrica y Física Aplicada (Complex Systems Group)

2) Media Laboratory, Massachusetts Institute of Technology, 75 Amherst St, Cambridge, MA 02139, Cambridge, Massachusetts, USA.

3) Instituto de Energía Solar, Dpto. Electrónica Física, Ingeniería Eléctrica y Física Aplicada , Universidad Politécnica de Madrid, Spain.

\begin{abstract}
Evaluating the probability of failure of a product during the warranty is key to estimating the cost of its entire life cycle. PV modules are the most reliable elements of a PV system and their high reliability translates into long warranty periods (typically 25 to 30 years). The number of photovoltaic modules that fail during warranty and when they failed is an important issue to estimate Life Cycle Cost of photovoltaic modules. In this paper we propose a coupled degradation-warranty model for PV modules. The proposed model is aimed to assess the probability of failure over time covered by warranty based on degradation data. This allows us to estimate the time of PV modules failure covered by the warranty. Although the warranty model has been applied to some forms of degradation and sales functions, our method can be applied to any real application. This allows the key parameters of the warranty to be obtained in a simple way. The required degradation parameters to fulfill warranty depends on the allowable ratio of warranted elements. However, as main conclusion of the influence of degradation rates on warranty is that it is not possible to fulfill 25 years of warranty if degradation rates are larger than $0,8 \% /$ year. The required degradation rates values, for 25 years of warranty, will be lower than $0,5 \% /$ year if the allowed warranted elements is in the range of $1 \%$.
\end{abstract}

\section{INTRODUCTION}

Photovoltaic (PV) modules are often regarded as the most reliable elements of PV systems[1$6]$. Their high reliability is indirectly reflected in the power output guarantees, which are currently in the range of 25 years (and may reach 30 years in the near future). In fact, PV modules have a very low total number of returns [6]. The reason for returns is usually due to catastrophic failures, in line with their long warranty. However, it is also known that the performance of PV modules constantly decreases over time when deployed outdoors. The degradation causes are very different and a good review that summarize the different causes and its potential risks in terms of degradation can be found elsewhere [7]. 
In this paper we analyze the warranty of photovoltaic modules taking into account the degradation of their power, as this is their main source of failure [8-11].There is an extensive literature on the degradation of photovoltaic modules related to several factors such as technology, quality or climatic conditions [12-15]. These studies show that the degradation of photovoltaic modules occurs in a very wide range depending on the factors described: from a minimum of $0,26 \% / y e a r$ to a maximum of 2,3\%/year [12] and this degradation can vary during their life. However, most manufacturers offer warranties in the same range: 25-30 years. With our analysis both manufacturers and customers will have a useful tool to evaluate if the photovoltaic modules comply with the warranties offered based on the degradation parameters.

Based on our analysis, we derive upper bounds for power degradation rate to fulfil long term warranties and we compare these results with real degradation data.

Warranty is a manufacturer's assurance issued to a buyer meaning that a product or service is or will be as represented [16]. There are three main elements in the warranty policy $[17,18]$ :

- Warranty period. This is the time during which the seller compromise to repair or replace a product that develops a fault. It is usually expressed in a time scale. However, for many products that are used intermittently (e.g. cars), the failure process is often more related to usage than to calendar time.

- Failure coverage. Normally, a warranty covers all failures due to defective materials or workmanship. However, damage caused by conditions other than normal use, such as accident, abuse, or improper maintenance, are usually excluded.

- Seller's and buyer's financial responsibility for warranty service. There are different warranty policies:

$\triangleright$ Free replacement policy. When a product fails within the warranty period and failure coverage, it is repaired or replaced by the seller free of charge to the buyer and warranted for the net remaining time.

$>$ Pro-rata replacement policy. Under this warranty, if an item fails before the end of the warranty period, it is replaced at a cost that depends on the age of the item at the time of the failure. This type of warranty is also sometimes called a partial warranty, since only a portion of the initial cost is covered. It is usually used for non-repairable items such as tires and batteries.

$\triangleright$ Combinations of free and pro-rata replacement policies.

In the particular case of photovoltaic modules a free replacement policy is usually applied. Under this policy, any item that fails during the warranty period is repaired or replaced free of charge. In the case of PV modules we will assume that the product is non repairable and therefore if an item fails during the warranty period, $W$, it will be replaced. The replacement item 
is then warranted for the time remaining in the warranty period. Therefore, the number of failures during the warranty period and when these failures occur is key to evaluating the life cycle cost of the product.

The warranty cost function depends on the number of failed items at each instant of time. It is therefore affected by both reliability and sales function. The latter corresponds to the time when the product begins to function.

On the other hand, assessing the cost of a product warranty can be difficult due to the following issues:

- A population of products can work in a wide variety of conditions of use that affect reliability such as

$\triangleright$ Location. Related to environmental stresses.

$\triangleright$ Application. Related to working stresses.

- Product reliability of different lots can vary considerably.

- When a minor failure occurs (due to excessive degradation), the customer may return the product immediately for warranty repair or may wait unless the warranty is about to expire.

- The warranty claiming process is strongly influenced by the customer's subjectivity.

- The population of products in service decreases over time, and manufacturers are often unaware of the number of failed units [19]. In warranty analysis, the sales volume is assumed to be working population, but it can be an overestimated value of the number of units in service. In the case of automotive market this overestimation can be significant due devastating accidents but in the case of photovoltaic market this overestimation will be lower.

Several contributions have addressed the issue of warranty before [16-18]. However, PV modules have their own specificities, the following being the ones that most seriously affect the cost of the warranty:

- The warranty period of a photovoltaic module, $W$, is at least twenty years, which is much longer than the selling time of an item. In this sense, it is not possible to use the warranty models of the automotive or electronics industry, where the warranty time and the selling time are similar.

- The new models of PV modules must be compatible with the previous ones so that they can be replaced.

- Unlike other products in the automotive or electronics sectors, where use is intermittent, the mode of operation of photovoltaic modules can be considered continuous. The main difficulty arises when, depending on the location, working conditions 
can vary significantly, which in turn affects the reliability of the photovoltaic module. In this paper we consider the influence of the location of the PV on the reliability function assuming a series of trends of degradation of the power of the PV modules.

This document is structured as follows. Right after the introduction, we establish the notation and a glossary of terms to facilitate reading in Section 2. The mathematical formulation of the model using this notation is presented in Section 3. Then in Section 4 we apply our warranty model to different scenarios. It is in this section, once we have presented the model, that we also include a comparison with previous results. Finally, we conclude with the most relevant aspects of our study.

\section{WARRANTY EVALUATION MODEL NOTATION}

Firstly, we set the notation for our model:

time parameters

$t$ (units: time - i. e. : years):time parameter whose origin represents when the first element, photovoltaic module in our case, is sold.

$\tau$ (units: time - i. e. : years): time parameter whose origin represents when a specific element, $i$ element in Figure 1, is sold. This time parameter coincides with the working time, time that the element is operating, since we assume that the product starts working right after it is sold. Reliability parameters are related with working time of the specific element. It is necessary to consider that in the model each specific element will have a reliability function depending on $\tau$ parameter.

$W($ units: time - i. e. : years): warranty period.

$L$ (units: time - i. e. : years): sales period.

We have represented the time parameters in Figure 1. At $t=0$ the first element is sold and all the elements are sold at $t \leq L$. Therefore, in connection with the warranty claim we can conclude:

- Elements failing before $W, t \leq W$, are covered by warranty.

- Elements failing after $L+W, t \geq L+W$ are not covered by warranty.

- Elements failing between these two periods, $W<t<L+W$ will be covered by the warranty or not depending on when they were sold. 


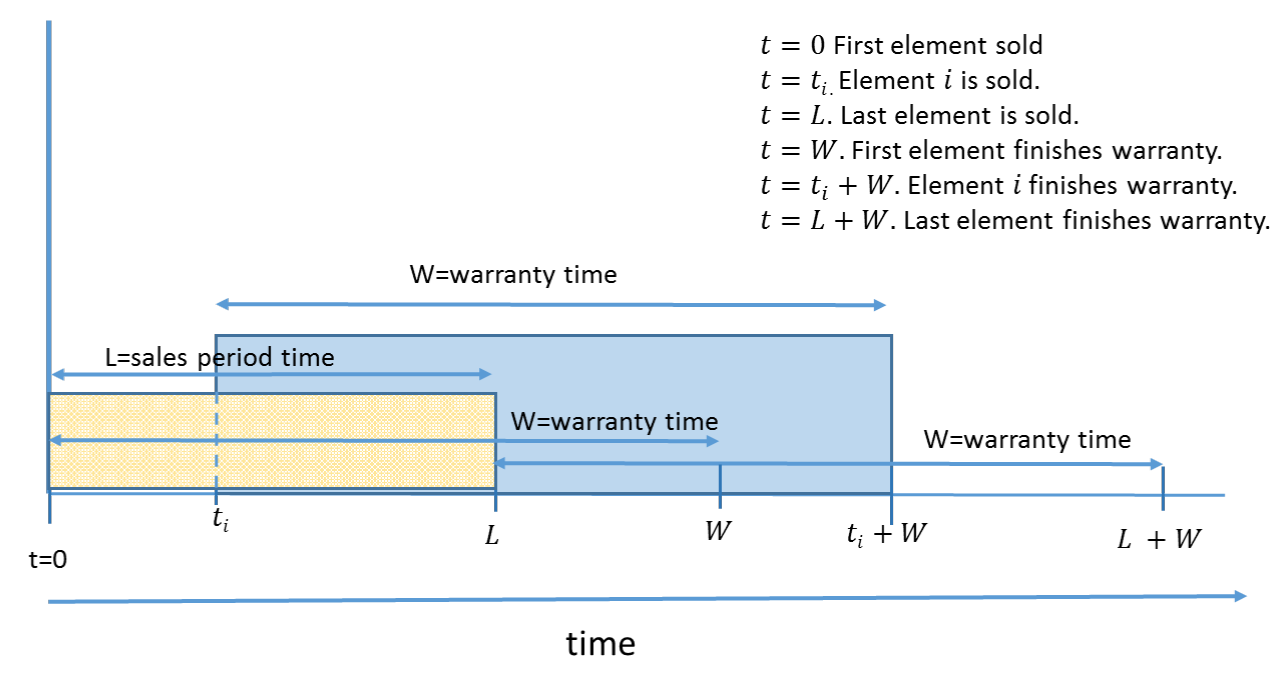

Figure 1: Diagram showing the time parameters and their relationship.

\section{Reliability functions}

Although the reliability functions for PV modules have been extensively described in a previous paper by the authors [20], the main reliability functions we use in this paper are:

$f(t)$ (units: probability of failure / unit time - i.e.: year ${ }^{-1}$ ): failure probability density function of elements sold at $t=0$. Describes the probability per unit of time that an element will fail assuming it has started working at $t=0$. Since it is a distribution function: $f(t) \geq 0$ and $\int_{0}^{\infty} f(t) d t=1$.

$F(t)$ (units: probability of failure - i.e: no units): failure cumulative distribution function of elements sold at $t=0$. It is the probability of an element failing before a time $t$.

$\gamma$ (units: probability of failure - i. e: no units): probability of an element failing during the warranty period, $W: \gamma=\int_{0}^{W} f(t) d t$.

\section{Sales function and elements sold}

$s(t)$ (units: density of elements sold/unit time:i.e.:year ${ }^{-1}$ : sales probability density function. Since it is a distribution function: $s(t) \geq 0$ and $\int_{0}^{\infty} s(t) d t=1$. Because all elements are sold in the sales period, $\mathrm{L}: \int_{0}^{L} s(t) d t=1$.

$S$ : Number of elements sold.

More details of $s(t)$ are explained in section 2.1.

Warranty functions. 
$v(t)$ (units: probability of failure / unit time - i. e.: year ${ }^{-1}$ ): failure density function for a set of products sold following a specific sales density function, $s(t)$. Compared with $f(t)$, $v(t)$ is delayed from $f(t)$ because the elements only start working after they are sold and not in $\mathrm{t}=0$. This function describes when products fail if they have been put to work following a sales density function, $s(t)$, and therefore $v(t)$ depends on both $f(t)$ and $s(t)$. Again, since it is a distribution function: $v(t) \geq 0$ and $\int_{0}^{\infty} v(t) d t=1$.

$v_{\text {warranty }}(t)$ (units: probability of failure / unit time - i.e.: year ${ }^{-1}$ ): failure probability function for elements in the warranty period. Failure function covered by warranty for a set of elements sold following a specific sales function $s(t)$. This function selects from $v(t)$ only those elements that are covered by warranty. As not all items that fail are covered by warranty, $v_{\text {warranty }}(t)$ is not a distribution function However it holds that: $v_{\text {warranty }}(t) \geq$ 0 and $\int_{0}^{\infty} v_{\text {warranty }}(t) d t \ll 1$.

$V_{\text {warranty }}(t)$ (units: probability of failure - i.e: no units) : cumulated failure probability function of elements failed in warranty period. $V_{\text {warranty }}(t)=\int_{0}^{t} v_{\text {warranty }}(t) d t$.

In Table 1 we collect the definition of all these quantities for reference.

\begin{tabular}{|c|l|}
\hline Parameter & \\
\hline$t$ & Time when the first PV is sold. \\
\hline$\tau$ & Time when a generic PV is sold \\
\hline$W$ & Warranty period \\
\hline$L$ & Sales period \\
\hline$f(t)$ & Failure probability density function \\
\hline$F(t)$ & Failure probability cumulative density function \\
\hline$\gamma$ & Probability of failure during warranty period \\
\hline$s(t)$ & Sales probability density function \\
\hline$S$ & Number of sold elements \\
\hline$v(t)$ & Failure probability density function given a specific sales function \\
\hline$v_{\text {warranty }}(t)$ & Failure probability function for elements in the warranty period \\
\hline$V_{\text {warranty }}(t)$ & Cumulated failure probability function of elements failed in warranty period \\
\hline
\end{tabular}

The following section describes the most important issues related to the sales function. 


\subsection{SALES FUNCTION}

From a marketing point of view, the product life cycle is defined as the curve representing the unit sales of a product from its date of entry into the market until its removed. In this traditional form, the product life cycle describes sales over time and is usually characterized by the following five phases [21]:

- $\quad$ Phase I: Introduction phase, when a new product is launched and sales are generally low.

- $\quad$ Phase II: Growth phase, when the sales grow quickly.

- $\quad$ Phase III: Maturity phase. During the maturity phase sales peak and the sales are roughly stable.

- $\quad$ Phase IV: Decline phase, when sales decrease until the product is removed from the market.

- $\quad$ Phase V: Phase-out stage, occurs when the manufacturer decides to stop the production of the product.

The sales function with these different phases depends on each specific product. In this regard, the Electronic Industries Association (EIA) [21] has defined the normal distribution as their standardized product life cycle curve. In this curve the mean value corresponds to the instant of time where the sales are maximum and the standard deviation is defined as the limit between different phases [22].

In Figure 2 we show an example of a product life cycle and its corresponding normal distribution with the different phases.

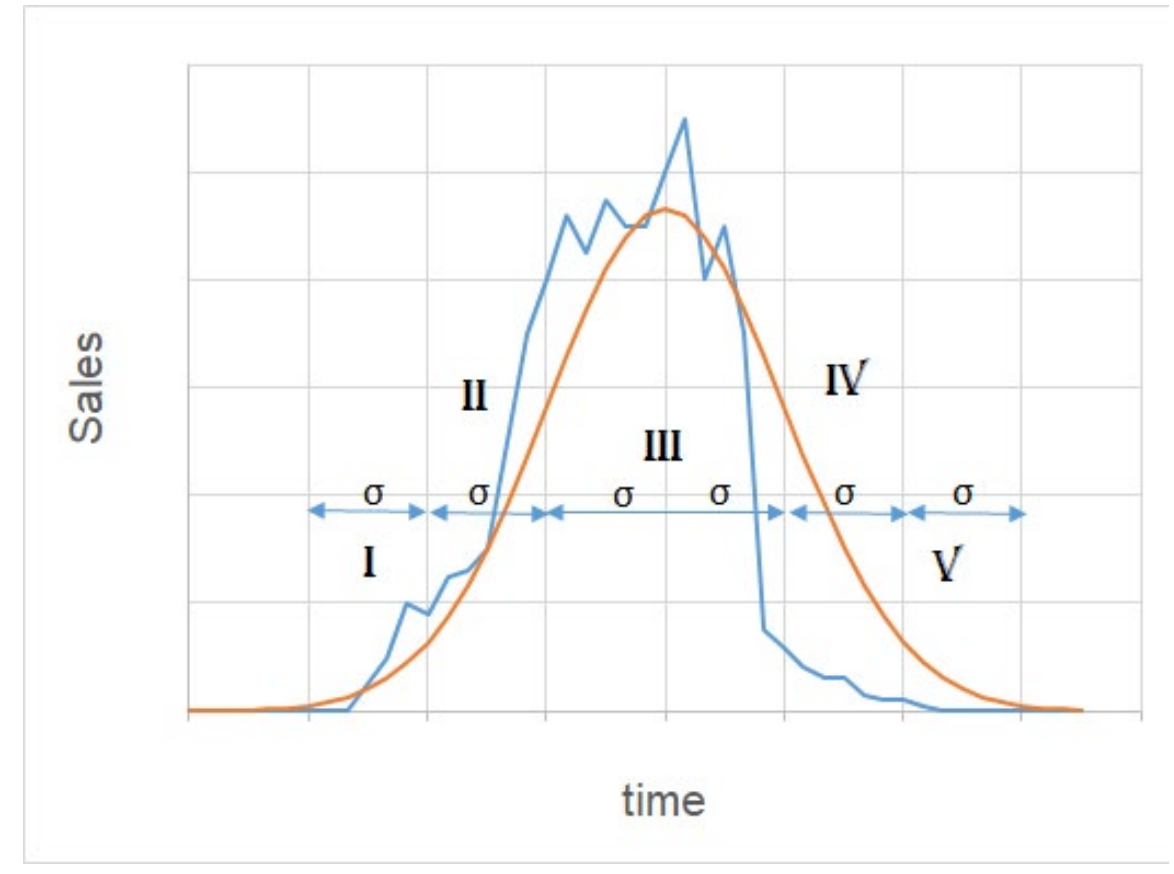

Figure 2: Sales function with the four different product life cycle phases. Sales values and time period depend on the specific product. Example of sales function (blue) and its normal distribution fit (orange), $\sigma$ is the standard deviation of sales normal distribution. 
Although each product has a different life cycle, in most cases they follow these five stages. Here we define the sales function, $s(t)$, that represents the sales distribution function with respect to time. If the sales period -including the five stages- is $L$, the total volume of sales $S$ renders:

$$
S=S \int_{0}^{L} S(t) d t
$$

In our approach we make the following assumptions related to the sales function:

- As stressed, due to the extremely long warranty periods of PV modules, we assume that: $W \gg L$.

- We focus our analysis to three different forms of the sales function: normal, constant and instantaneous (i.e. Dirac-delta type), to cover a wide range of possible scenarios.

\section{WARRANTY MODEL DEVELOPMENT}

With the warranty claim model we use in this work we can obtain relevant information such as

1. The number of modules failing during the warranty period: $\gamma$. This factor is very important for evaluating the warranty costs associated with PV modules and it will be evaluated from the degradation parameters. Therefore, one can set an acceptable percentage of unit failures in terms of warranty cost and manufacturer reputation.

2. The failure probability function for products in the warranty period, $v_{\text {warranty }}(t)$, which informs us when the modules under warranty fail. This function is very important from the point of view of spare parts logistics.

Taking into account these considerations, our model focuses on evaluating both the number of items that fail in the warranty period, $\gamma$, and the failure times, $v_{\text {warranty }}(t)$. We develop our model in the following sections.

\subsection{EVALUATION OF THE PERCENTAGE OF MODULES THAT FAIL IN WAR- RANTY PERIOD}

Notice that the cumulated failure probability during the entire warranty period, $W$, does not depend on when a specific element is released, $s(t)$. Hence, $\gamma$ can be obtained from the failure probability density function, $f(t)$ directly:

$$
\gamma=\int_{0}^{W} f(t) d t
$$

This allows to estimate the expected number of elements to be claimed during the warranty period in a straightforward manner.

To evaluate not only how many elements fail, but also when they fail during the warranty period, we define the time distribution of returned modules in warranty period: $v_{\text {warranty }}(t)$. This is the failure probability density function within the warranty period taking the origin of 
times at the time the first element is sold. To evaluate this function, we make the following assumptions:

- Elements are put into use immediately after purchase and therefore the sales function, $s(t)$, coincides with the time function of when the product starts working.

- Free replacement policy. When an element fails within the warranty period, the seller will either repair or replace it at no charge to the buyer. As assumed, photovoltaic modules are not repairable; they are replaced directly.

- The warranty period, $W$, exceeds the sales period, $L$, due to the long warranty period of PV modules.

- A replaced element will not fail again, and the replacement time of a failed element is negligible compared to its failure time. This assumption is realistic if we analyze $F(t)$ during the warranty period.

- The products are high quality manufactured and therefore infant failures will be neglected.

- The predominant failure mechanism is degradation, as it has been observed by several authors [8-15].

In our model, two time parameters with different origin are relevant, see Figure 1:

- $t$, whose origin is set when the first element is sold.

- $\tau$, which is 0 when the specific element under consideration is sold. Therefore, a failure of such element is covered by warranty if it fails before $\tau+W$.

When elements fail, taking $t$ as time parameter, depends on both sales and failure density functions. We can combine both effects by means of the convolution expressed in Eq.(3):

$$
v(t)=\int_{0}^{t} s(\tau) f(t-\tau) d \tau
$$

In this expression we include all failed elements, regardless of whether they fail within the warranty period or not. However, in the evaluation of the warranty analysis we have to consider only the elements that fail during the warranty period. In Figure 1 we describe the sales and warranty periods setting $\mathrm{t}=0$ to the instant of time when the first element is sold. It is clear from the figure that not all the items fail during the warranty period.

Now we have to distinguish three cases. In the two extreme cases, $\mathrm{t} \leq \mathrm{W}$ and $t>W+L$ it can be assesed directly if the failed elemets are covered by waranty or not. All the elements that fail in $\mathrm{t} \leq \mathrm{W}$ are covered by warranty and all the elements that fail in $t>W+L$ are not covered by warranty. In the intermediate case, elements that fail during $W<t \leq W+L$, it is necessary to know when the failed element has been sold. Therefore, the three cases are:

- If the failures occur within the warranty time with respect to the time of sale of the first element, $t \leq W$, then all the failures will occur during the warranty period. Then Eq.(3) renders: 


$$
\begin{gathered}
t \leq W \\
v_{\text {warranty }}(t)=\int_{0}^{t} s(\tau) f(t-\tau) d \tau
\end{gathered}
$$

- If failures occur after the warranty period with respect to the time of sale of the first element $(t>W)$ then products will be covered by warranty or not depending on when they have been sold, $\tau$,. If the products fail before $W+\tau$, they will be covered by warranty and if they fail after $W+\tau$ they will not. In this case Eq.(3) is transformed into:

$$
\begin{gathered}
W<t<W+L \\
v_{\text {warranty }}(t)=\int_{t-W}^{t} s(\tau) f(t-\tau) d \tau
\end{gathered}
$$

- In this expression (Eq.(5)) notice that if failures occur after the sales period plus the warranty period with respect the first product sold, $t>W+L$, the failures will not be covered by warranty.

$$
\begin{gathered}
t>L+W \\
\boldsymbol{v}_{\text {warranty }}(t)=0
\end{gathered}
$$

In the following we will apply this model to PV modules. Therefore, we need to fix both $f(t)$ and $s(t)$. For degradation we will use the model described by the authors in a previous paper [20]. For the sales function, $s(t)$, we have analyzed different cases based on the literature $[21,22]$.

\subsection{FAILURE DENSITY FUNCTION OF PHOTOVOLTAIC MODULES.}

Photovoltaic modules can fail for various reasons. During their lifetime, failures can occur in three different stages that occur in the following order:

- $\quad$ Period of infant mortality, with a decreasing failure rate. Here, manufacturing failures appear caused by product design deficiencies, poor quality control, process control, or labor during manufacture or installation. The warranty period usually covers these types of failures.

- $\quad$ Random failure period with a constant low failure rate. This corresponds to a random failure occurring during the service life period.

- Wear-out period with an increasing failure rate. Here failures become more frequent due to product degradation. 
Most products have a warranty period of about two years, intended to cover the period of infant mortality. However, due to the long warranty period of PV modules (over 20 years), warranty failures can occur in all three periods of the product's life.

In previous works $[6,11,20]$ infant and random failures of PVs have been observed to be rare and most of them appear in the wear period due to performance degradation. This occurs when PV modules have been in operation for several years.

In [20] we developed a model to evaluate the reliability of photovoltaic modules based on the evolution of their power in the event of degradation failures. We summarize the model and its main elements below.

Degradation failure occurs when the power of a photovoltaic module falls below a limit, $P_{\text {limit }}$. In this way reliability is the probability that a module has not yet failed (i.e. has a power above $\left.P_{\text {limit }}\right)$. In our model the power of the photovoltaic modules follows a normal distribution that varies in time with the following performance:

- At $\mathrm{t}=0$ the average power is the nominal power, $P_{0}$, and the standard deviation is very low, $\sigma_{0}$. Therefore, the probability of a PV module being under its power limit $\left(80 \%\right.$ of $\left.P_{0}\right)$ is almost negligible and the reliability is almost 1 (see Figure 2 from our previous work [20] for reference).

- While the average power decreases over time, the standard deviation increases over time. Therefore, the probability that the power of the module decreases below $P_{\text {limit }}$ increases with time and its reliability decreases. In our analysis we assume a simple linear model with $\mu(t)$ as the mean power and $\sigma(t)$ as the standard deviation.

According to our model [20], unreliability is the probability that the power of the PV module becomes lower than the power set as degradation failure (Eq.(7)).

$$
F(t)=\int_{0}^{P_{\text {limit }}} p(P, t) d P=\Phi\left(\frac{P_{\text {limit }}-\left(P_{0}-A t\right)}{\sigma_{0}+B t}\right)
$$

Here: $\Phi$ is the cumulative probability function for the normal distribution, $A$ is the yearly decrease in the average power module in $W_{p} / y e a r$, and $B$ is the yearly increase in standard deviation in $W_{p} / y e a r$. Finally, the time $t$ is measured in years.

Once $F(t)$ has been evaluated, the failure probability density function can be easily computed through $f(t)=\frac{d F(t)}{d t}$. Therefore, based on this model, knowing the degradation rate parameters $(A$ and $B$ ) one can evaluate the failure probability density function, $f(t)$, for any photovoltaic module. Since $A$ and $B$ depend on the location of the PV module and since their value can affect the overall performance of the module, we include an analysis of the influence of both parameters in this paper. 


\section{WARRANTY MODEL APPLICATION}

Here we apply the model described above to the case of PV modules. As highlighted in the previous section, several aspects related with warranty claims will be discussed. We start with the percentage of PV modules returned during the warranty period and then we analyze when the failures covered by the warranty occur.

\subsection{PERCENTAGE OF PHOTOVOLTAIC MODULES RETURNED DURING WAR- RANTY PERIOD}

Considering the degradation-based reliability model described in previous works [20,23] and according to Eq.(7), the probability of a specific PV module failing during its warranty period can be expressed as:

$$
\gamma=\int_{0}^{W} f(t) d t=\Phi\left(\frac{P_{\text {limit }}-\left(P_{0}-A W\right)}{\sigma_{0}+B W}\right)
$$

In the case of $W=25$ years, after normalizing the nominal power $\left(P_{0}=1\right)$, we set the failure limit to $80 \%$ of the nominal power $\left(P_{\text {limit }}=0,8\right)$, Also, if we assume a tolerance of $\pm 3 \%$ at the initial stage (i.e. we consider that the standard deviation at that initial stage is $\frac{3 \sigma_{0}}{P_{0}}=0,03$ ), we find:

$$
\gamma=\Phi\left(\frac{0,8-\left(1-\frac{A}{P_{0}} 25\right)}{0,01+\frac{B}{P_{0}} 25}\right)=\Phi\left(\frac{-0,2+\frac{A}{P_{0}} 25}{0,01+\frac{B}{P_{0}} 25}\right)
$$

Since $\Phi$ is a tabulated, the $\gamma$ parameter can be calculated for any $\frac{A}{P_{0}}$ and $\frac{B}{P_{0}}$ degradation values.

Therefore, the probability of a PV module failing during the warranty period depends on its degradation, which is quantified by the evolution of its power. We capture this evolution through the first two statistical moments, the mean and the standard deviation, (we comment on the effect of the distribution skewness in section 4.3).

Based on this model, in Figure 3 we represent $\frac{A}{P_{0}} v s \frac{B}{P_{0}}$ for different percentage of failures at the end of the warranty period. It can be seen that when one of these parameters increases, the percentage of failures also increases. Also, after 25 years of warranty period, if $\frac{A}{P_{0}}=0,008 /$ year (yearly degradation rate of $0,8 \%$ /year), the average power decreases $20 \%$ of its value. Therefore, in this case of a normal failure distribution, $50 \%$ of the modules will have failed during the warranty period, which is not acceptable for any product. 


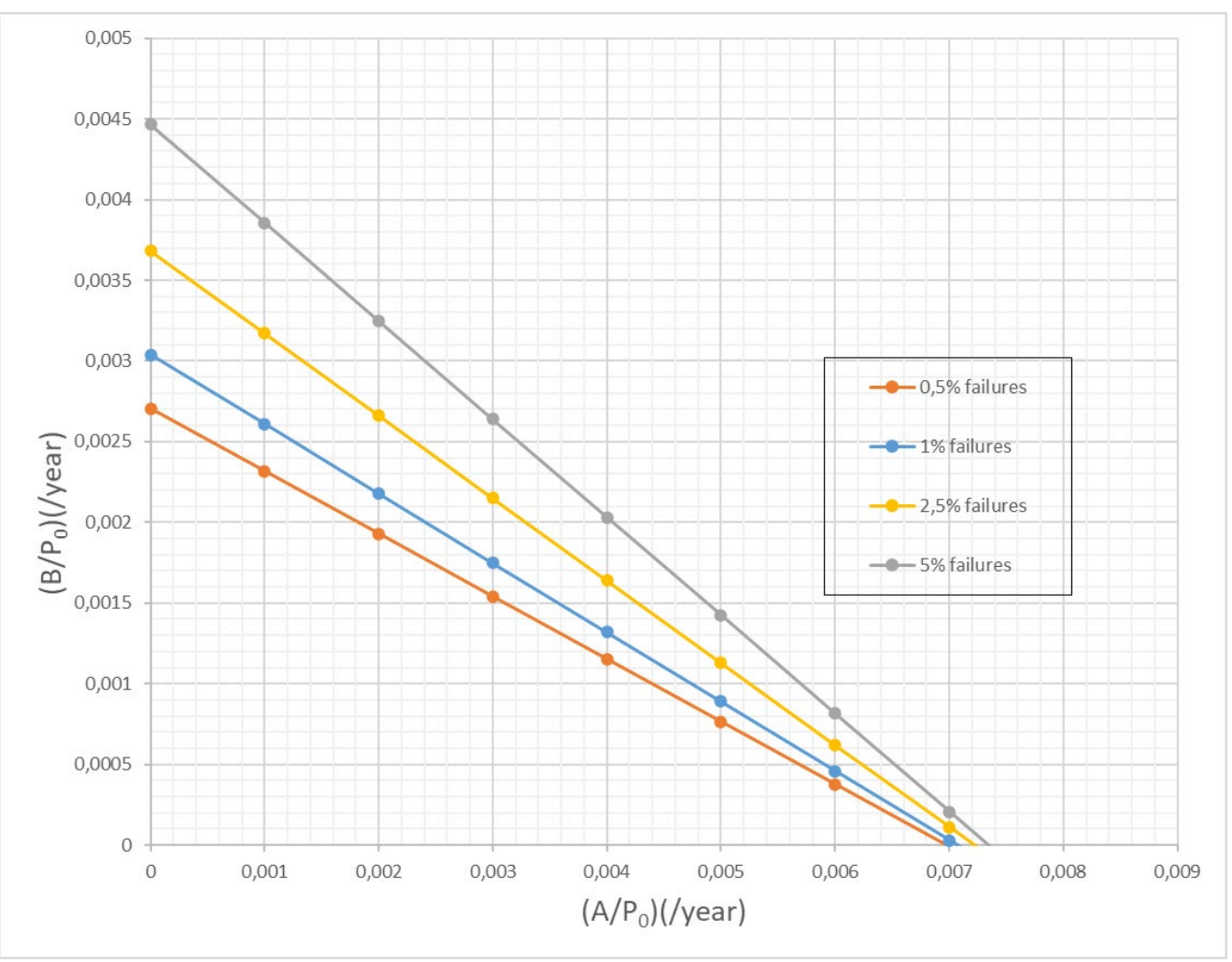

Figure 3: Standard degradation rate vs mean degradation rate for different percentage of failure at the end of the warranty period (assuming that standard deviation at $t=0$ is 0,01 )

We have also analyzed the influence of the degradation rate of the standard deviation of the power, $\frac{B}{P_{0}}$. We start with a value of $0,001 /$ year, which means that after 10 years the power standard deviation has doubled. Then we increase the parameter up to 0,003/year, (after 10 years the power module standard deviation is four times larger than its initial value). In Figure 4 we represent $F(t)$, the unreliability -or cumulated probability of failure-, at the end of the warranty time with respect to the mean power for different $\frac{B}{P_{0}}$ values. From this figure it can be concluded that:

- In order to have less than $5 \%$ of the failures during the warranty time, the degradation rate must be smaller than $0,57 \% /$ year if $\frac{B}{P_{0}}$ is $0,1 \% /$ year (blue line at the right) and smaller than $0,24 \% /$ year if $\frac{B}{P_{0}}$ is $0,3 \% /$ year (gray line).

- In order to have less than $1 \%$ of the failures during the warranty time, the degradation rate must be lower than $0,47 \% /$ year if $\frac{B}{P_{0}}$ is $0,1 \% /$ year (blue line at the right) and practically $0 \% /$ year if $\frac{B}{P_{0}}$ is $0,3 \% /$ year (gray line).

Therefore, it is not possible to fulfill 25 years warranty with degradation rates above $0,8 \%$ /year. Depending on both the portion of failures allowable during warranty time and the standard degradation rate, the required degradation rate must be much smaller; in the range of $0,5 \% /$ year. 


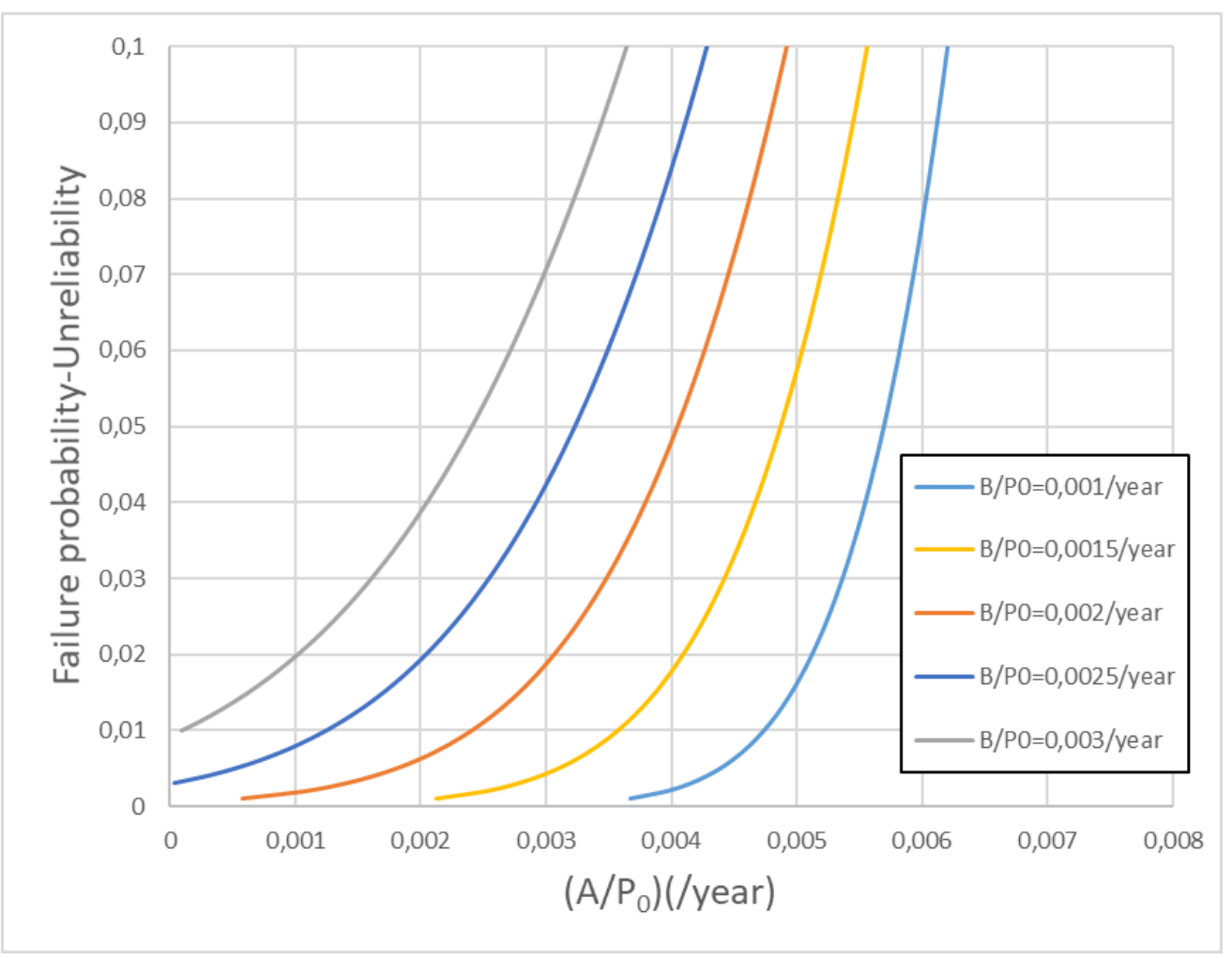

Figure 4: Unreliability at the end of the warranty period, 25 years, vs average power degradation, $\frac{A}{P_{0}}$, rate for different power standard deviation rate, $\frac{B}{P_{0}}$.

Below, several works related to the degradation of in field PV modules developed during the last years are analyzed. The main results obtained for the effects of both the mean degradation rate, $\frac{A}{P_{0}}$, and the standard deviation degradation rate, $\frac{B}{P_{0}}$, are summarized here:

- Regarding the mean degradation rates, NREL [13] developed a reference compendium of PV degradation rates from more than 1000 degradation rates in almost 200 studies from 40 different countries. The authors focused their analysis on high quality Si crystalline PV modules degradation rates at different locations. It was noticed that the snow environment was the most benign with a $0,35 \%$ /year median degradation rate and $0,62 \% /$ year mean degradation rate, On the other hand, desert turned out to be the most aggressive, with $0,71 \%$ /year median degradation rate and $1,19 \%$ /year mean degradation rate. Other environments like hot and humid and moderate reported intermediate degradation rates. In all the environments analyzed the mean parameter was larger than the median. This implies a right long-tailed asymmetric distribution with large values of degradation rate that significantly affects the distribution mean. Since the position of the median is less sensitive to extreme values than the mean we choose the median parameter as a reference. A recent work [12] that analyses large-scale grid-connected solar photovoltaic power plant in different locations reports degradation rates between a minimum of $0,26 \%$ year and a maximum of $2,3 \% /$ year, with an average of $0,71 \% /$ year depending on the climatic environment 
considered. Other authors agree that these degradation rates are in the range of $0,5 \% /$ year in template climates [24] and larger than 1\%/year in desert climate [25]. We analyze the influence of location in Section 4.3 below.

- Regarding the evolution of the power standard deviation, several studies deal with the data of a set of photovoltaic modules, but there is no equivalent compendium for this parameter as for the power mean. From different studies showing the histograms of the power of the photovoltaic modules aged in the field, it can be seen that the standard deviation increases significantly over time. Although in all cases the standard deviation increases, the trend changes according to the module and location. Taking as reference the study of Humboldt State University [26] the standard deviation rate, $\frac{B}{P_{0}}$, is $0,00215 /$ year $(0,215 \% /$ year $)$. However, since this value refers to a specific module and location, our analysis has been carried out for a set of $\frac{B}{P_{0}}$ values instead (see Figure 4). In Table 1 we show both $\frac{A}{P_{0}}$ and $\frac{B}{P_{0}}$ values for a $0,5 \%$ and $5 \%$ of returned PV modules during the warranty period according to Figure 4. A recent study [27] reports a $\frac{B}{P_{0}}$ value of $0,5 \% /$ year, standard deviation rate. But, according to our model, it is not possible to fulfill a warranty of 25 years with this standard deviation increasing rate.

\begin{tabular}{|c|c|c|c|c|c|c|c|c|}
\hline$\frac{B}{P_{0}}(\% /$ year $)$ & 0,00 & 0,10 & 0,20 & 0,215 & 0,25 & 0,30 & 0,35 & 0,40 \\
\hline $\begin{array}{l}\frac{A}{P_{0}} \quad(\% / \text { year }) \\
(0.5 \% \text { returned })\end{array}$ & 0,70 & 0,44 & 0,18 & 0,14 & 0,05 & $\begin{array}{l}\text { Not } \\
\text { possi- } \\
\text { ble }\end{array}$ & $\begin{array}{l}\text { Not } \\
\text { possi- } \\
\text { ble }\end{array}$ & $\begin{array}{l}\text { Not } \\
\text { possi- } \\
\text { ble }\end{array}$ \\
\hline $\begin{array}{l}\frac{A}{P_{0}} \text { (\%/year) }(5 \% \\
\text { returned })\end{array}$ & 0,73 & 0,57 & 0,41 & 0,38 & 0,32 & 0,24 & 0,16 & 0,08 \\
\hline
\end{tabular}

Table 1: $\frac{A}{P_{0}}$ and $\frac{B}{P_{0}}$ values for a $0.5 \%$ and $5 \%$ of returned photovoltaic modules during warranty period.

The main conclusions of Table 1 are:

- $\quad$ By assuming a maximum of $5 \%$ of returned modules and if the mean degradation rate is equal or larger than $0,73 \%$ /year $\left(\frac{A}{P_{0}} \geq 0,73 \%\right.$ /year $)$, it is not possible to fulfill 25 years of warranty. This value is evaluated assuming that the standard deviation at $\mathrm{t}=0$ is 0.01 and that it remains constant during degradation.

- If we consider a $0,5 \%$ of the returned modules, it is not possible to fulfill 25 years of warranty if the mean degradation rate is equal or larger than $0,70 \% /$ year $\left(\frac{A}{P_{0}} \geq 0,70 \% /\right.$ year $)$. This value is evaluated assuming that the standard deviation at $\mathrm{t}=0$ is 0,01 and that it remains constant during degradation. When the proportion of returned 
modules is so low, the required degradation rate to fulfill the warranty is significantly affected by parameter B (see Figure 4).

- $\quad$ Noting that the standard deviation increases with time, and using the reference value found in the literature: $\frac{B}{P_{0}}=0,215 \% /$ year [26], the average rate of degradation should not be higher than $0,38 \% /$ year, $\frac{A}{P_{0}}<0,38 \% /$ year to comply with a 25 -year warranty for $5 \%$ of the return modules. If only $0,5 \%$ of the return modules are allowed, the mean degradation rate must not exceed $0,18 \%$ year, $\frac{A}{P_{0}}<0,18 \% /$ year in order to comply with a 25 -year warranty. Other standard deviation rates for $0,5 \%$ and $5 \%$ of returned modules are shown in Table 1.

\subsection{FAILURE DENSITY FUNCTION COVERED BY WARRANTY. CASE STUDY}

As stressed, the failure density function covered by the warranty depends on both the failure probability density and the sales function. We now propose our warranty model based on a case study. In this analysis we assume a $\frac{A}{P_{0}}=0,35 \% /$ year, which is the median value found in the literature for a benign environment [13], and $\frac{B}{P_{0}}=0,215 \% /$ year, which is a value reported in [26].

In Figure 5 we show both the failure probability density function and the cumulated failure probability density function. A first conclusion from this figure is that the failure rate during the warranty period ( 25 years) is $3,9 \%$, which, depending on the manufacturer's policy, may or may not be acceptable. 


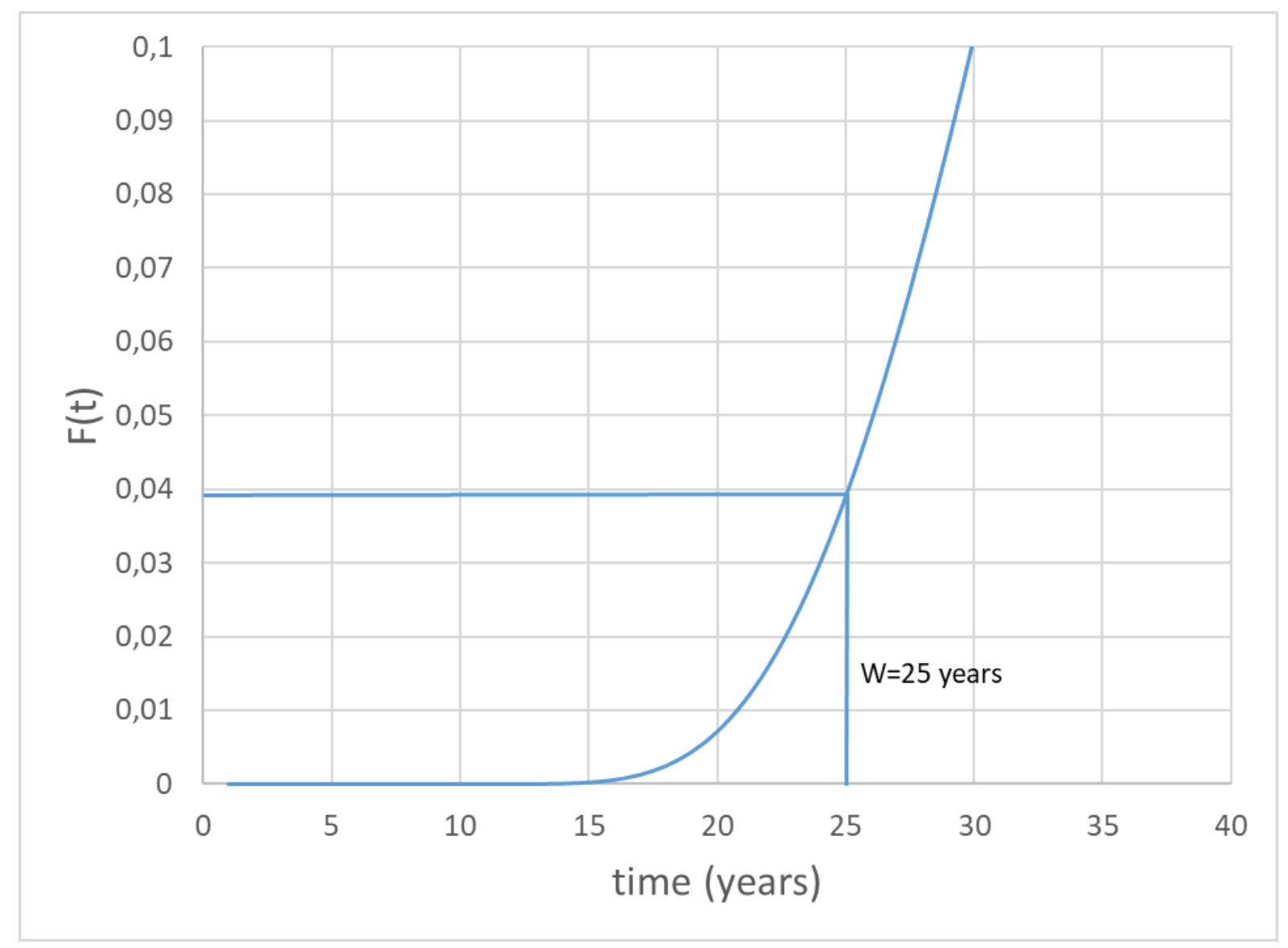

Figure 5: Probability density function and cumulated density function for the selected Case Study

Once we have assessed that $3,9 \%$ of the items failed during the warranty period, it is important to know when they fail. To analyze when the elements covered by the warranty fail, it is necessary to consider not only the degradation parameters, but also the selling function (see Eq.(3) in Section 3.1)

In relation to the sales function, we analyze three different cases (see Figure 6):

- $\quad$ Case 1, where all the elements are sold at $t=0$.

- $\quad$ Case 2, where all the elements are sold uniformly. In Figure 6 we represent a uniform sales distribution in a period of time of 10 years.

- $\quad$ Case 3, where the elements are sold following a normal distribution. In Figure 6 we show the corresponding sales distribution with an average of 5 years and a standard deviation of twenty months $\left(\sigma=\frac{\mu}{3}\right)$. Selecting a standard deviation of a one third of mean parameter ( 5 years equal to 60 months) the shape of sales normal is similar to Figure 6. 


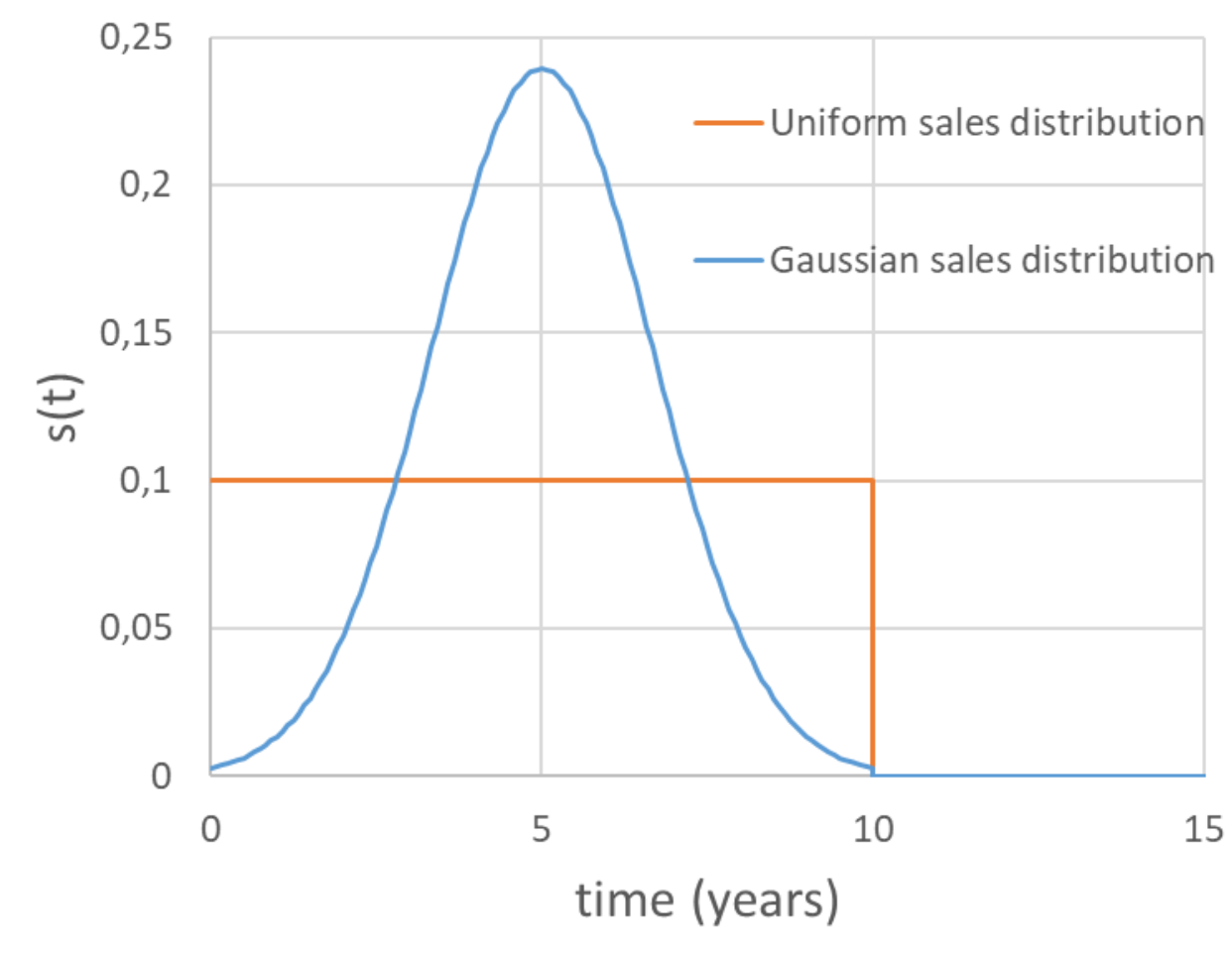

Figure 6: Uniform distribution and normal distribution sales function

Based on the model described in section 3 we have evaluated $V_{\text {warranty }}(t)$ for the following values of the degradation parameters: $\frac{A}{P_{0}}=0,35 \% /$ year and $\frac{B}{P_{0}}=0,215 \% /$ year. We discuss below the main results obtained from the three cases.

\subsubsection{CASE 1: WARRANTY ASSESMENT WHEN ALL PV MODULES ARE SOLD AT $t=0$.}

Here we focus on the cumulated time distribution of failed modules during warranty $V_{\text {warranty }}(t)$ when all the PV modules are sold at the initial stage. In this case all modules that fail before the warranty since the first item is sold will be covered by the warranty. On the other hand, all modules that fail after the warranty time since the first item is sold will not be covered by the warranty. Therefore $V_{\text {warranty }}(t)$ renders:

$$
\begin{aligned}
& V_{\text {warranty }}(t)=F(t) \text { if } t \leq W \\
& V_{\text {warranty }}(t)=F(W) \text { if } t>W
\end{aligned}
$$




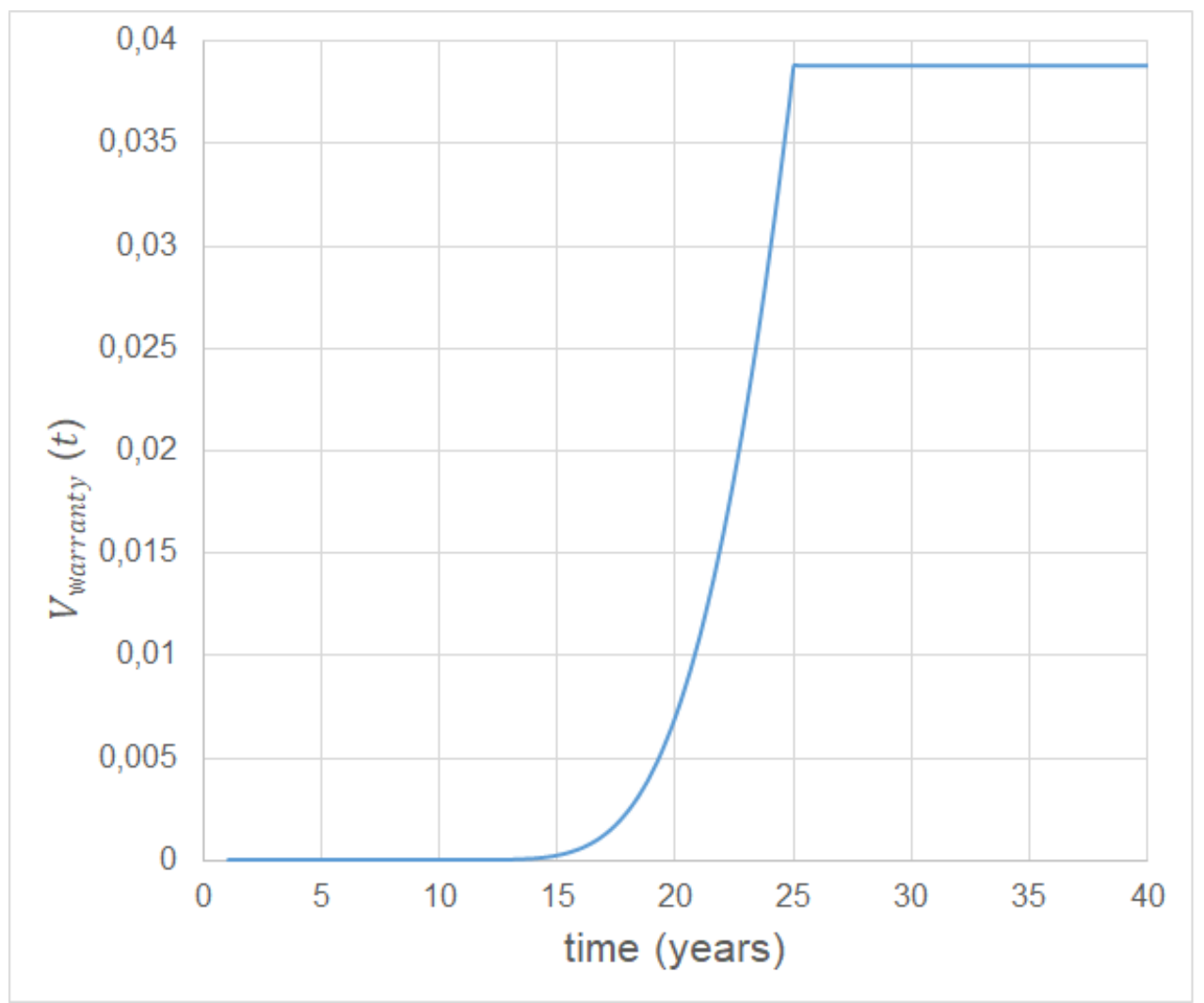

Figure 7: $V_{\text {warranty }}(t)$ in Case 1, all the elements are sold at the initial stage.

We represent $V_{\text {warranty }}(t)$ in Figure 7 , from which we derive the following conclusions:

- $\quad$ There is no significant number of degradation failures during the first 10 years of the PV module's life and this must be considered in the replacement logistics. After that period, claims will increase considerably.

- $\quad$ Given the reference values for $A$ and $B: \frac{A}{P_{0}}=0,35 \% /$ year and $\frac{B}{P_{0}}=0,215 \% /$ year, the percentage of failed elements covered by the warranty is $3,9 \%$ of the total products. Notice that this percentage depends only on the degradation parameters $(A$ and $B)$ and not on the sales function.

- $\quad$ All photovoltaic modules that fail before the warranty with respect to the first element sold are covered by the warranty.

- All photovoltaic modules that fail after the warranty with respect to the first element sold are not covered by the warranty.

In the following sections we evaluate $V_{\text {warranty }}(t)$ considering different sales functions and we compare the results obtained with Case 1. 
Here we fix the degradation parameters $A$ and $B$ values and we use a uniform sales distribution (see Figure 6). We vary the sales distribution uniformly from 2 to 20 years. For example, a uniform distribution with a time interval of 5 years will mean that the sales occur uniformly from $t=0$ to $t=5$ years (i.e. $20 \%$ of the sales in each year or $0,0548 \%$ of the sales daily $(100 / 5 \times 365))$. In Figure 8 we show $V_{\text {warranty }}(t)$ for Case 1 and different uniform sales distribution from 2 to 20 years.

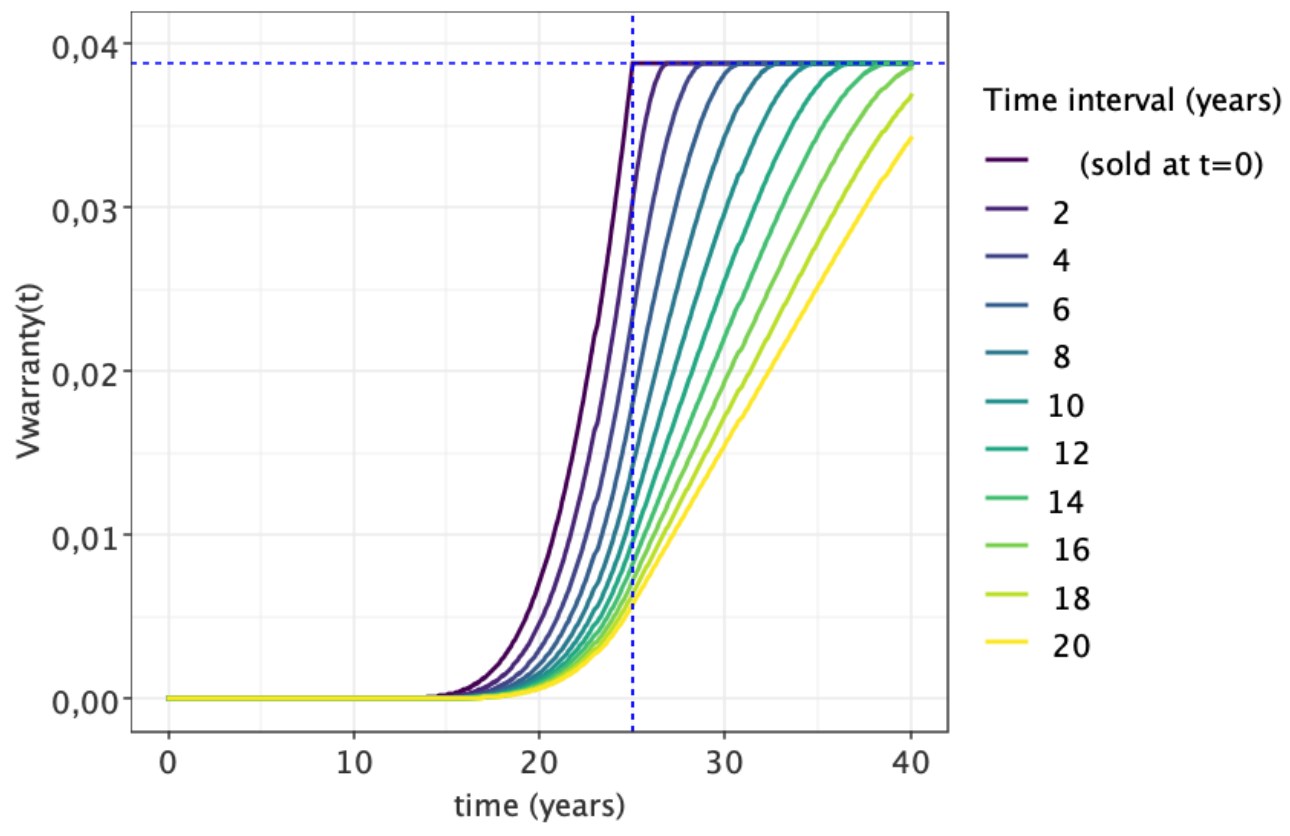

Figure 8: $V_{\text {warranty }}(t)$ in Case 2, the elements are sold with an uniform distribution function (from 2 years to 20 years)

From this figure we conclude:

- $\quad$ The number of degradation failures during the first 10 years of PV module life is not significant and this must be considered in the replacement logistics. After that time, possible warranty claims will probably increase considerably.

- $\quad$ As in Case 1, for the reference values $A$ and $B$ the elements that fail covered by warranty are $3,9 \%$ of the total. Again, this percentage depends only on the degradation parameters $(A$ and $B)$ and not on the sales function.

- The time of failure covered by the warranty depends on the sales function. Notice now how the $V_{\text {warranty }}(t)$ function is delayed by increasing the period of sale with respect to Case 1 (all the elements sold at $\mathrm{t}=0$ ). For example, in the case of a time interval of 10 years, the last item covered by the warranty will be at 35 years $(L+W$ in Figure 1). 
Based on the results from Figure 8 we also show in Figure 9 the expected time (horizontal axis of Figure 8 ) to reach a certain percentage of failed items during the warranty. This Figure is very useful for estimating in advance how many spare elements are needed. For example, if we have a uniform distribution of sales covering a 10-year interval, during the first 23 years it will be necessary to have $1 \%$ of spare PV modules available.

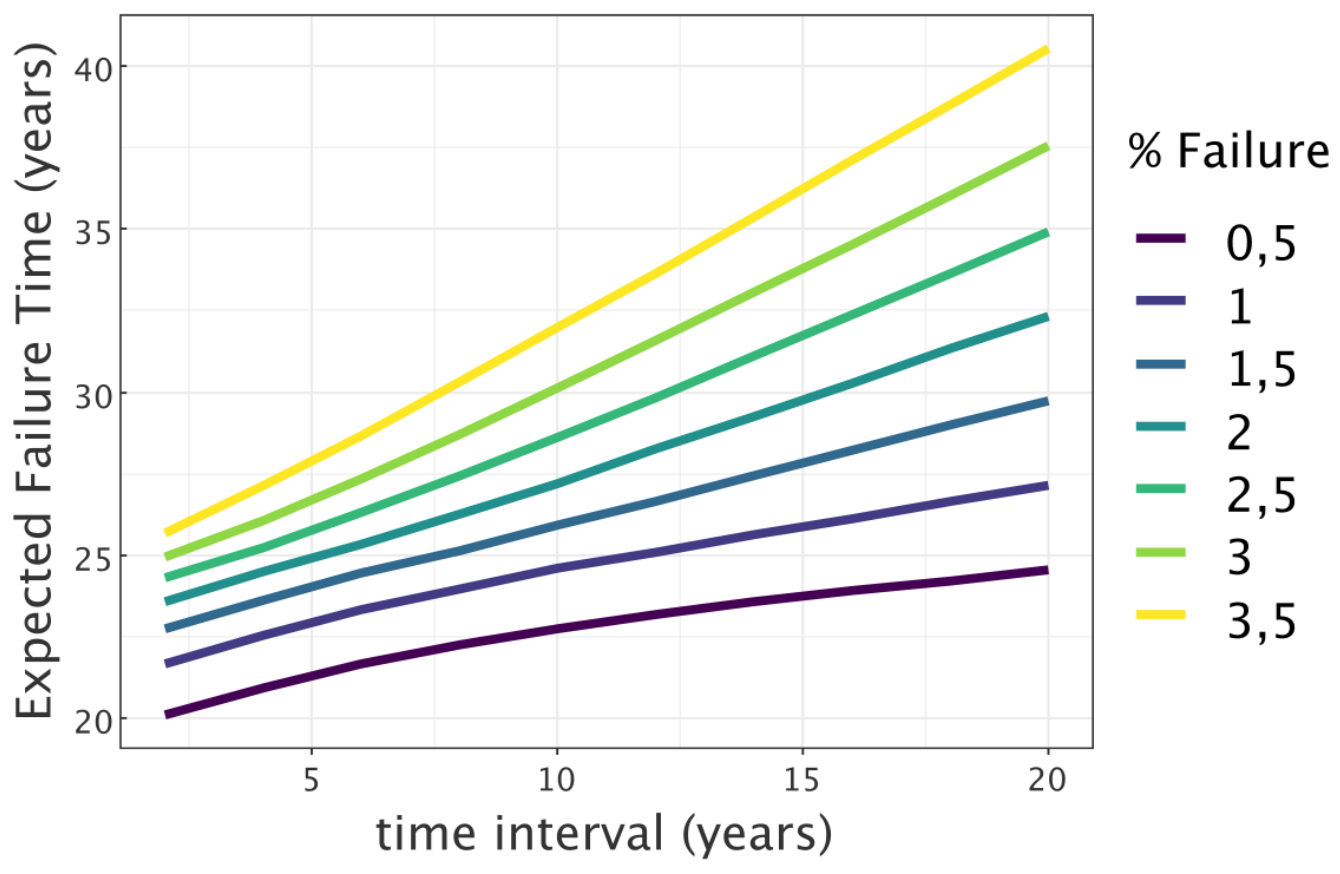

Figure 9: Expected failure time vs time interval of uniform sales distribution for different percentage of failed elements covered by warranty.

\subsubsection{CASE 3: WARRANTY ASSESMENT UNDER NORMAL SALES DISTRIBUTION}

We now perform the same analysis but using a normal distribution for the sales function instead. To emulate the normal distribution shown in Figure 3, where the sales starts at $\mathrm{t}=0$, we have assumed that the standard deviation $\sigma$, is one third of the mean, $\sigma=\frac{\mu}{3}$. This ensures that the cut-off of the normal will have little effect on the results. Thus, the normal sales distribution is defined by a unique parameter, $\mu$.

In Figure 10 we show $V_{\text {warranty }}(t)$ for the Case 1 sales function and different normal sales distribution (from 5 to 12 years) . 


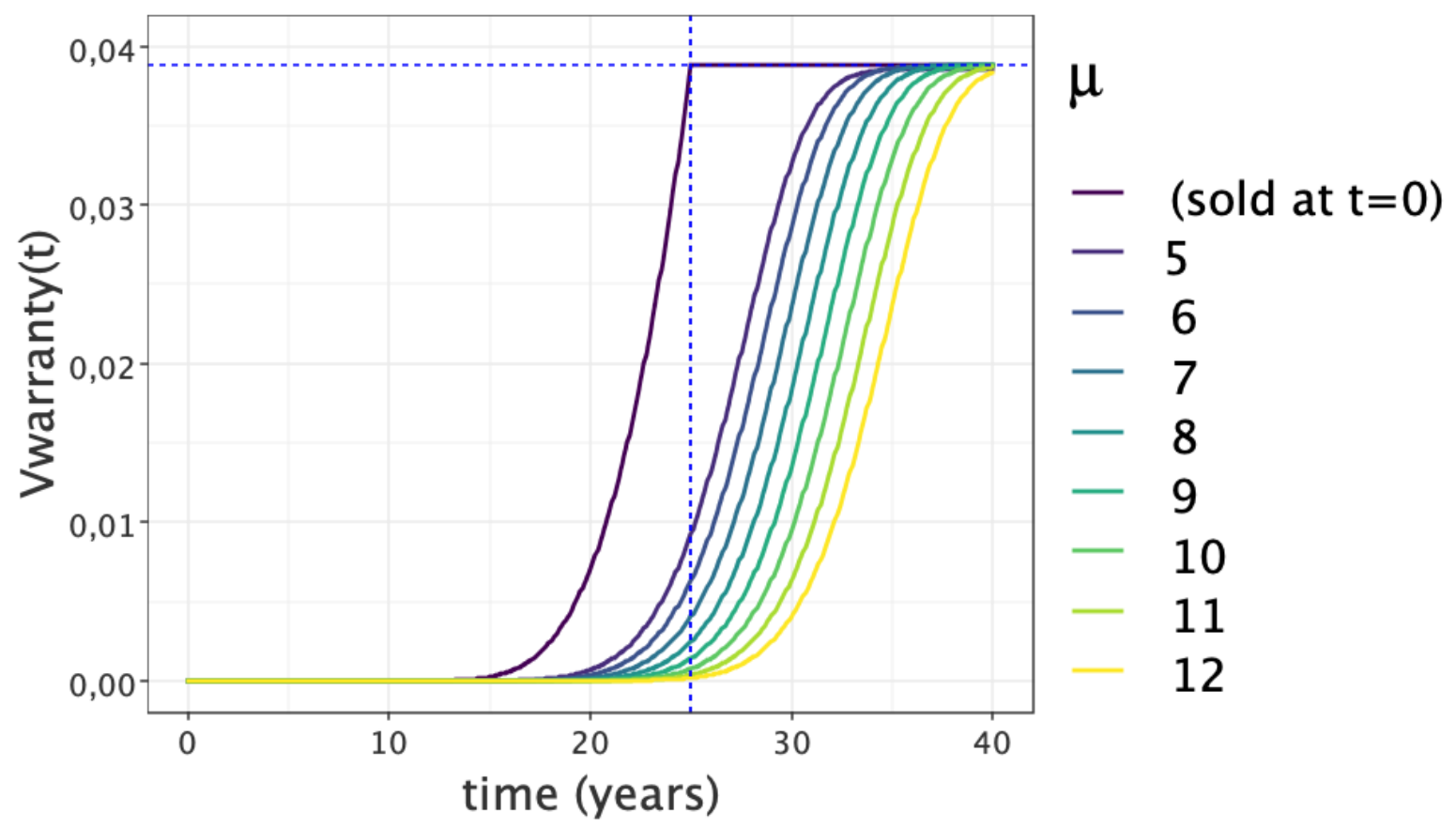

Figure 10: $V_{\text {warranty }}(t)$ in Case 3,the elements are sold with normal distribution function (from 5 years to 12 years).

We highlight the following facts:

- In the long term the probability of failure of PV modules covered by the warranty does not depend on the sales distribution. Furthermore, considering the reference values of $A$ and $B$ as before, the elements that fail covered by warranty are again 3,9\%. Therefore, this percentage depends only on the degradation parameters $(A$ and $B)$ and not on the sales function.

- Warranty failure times depend on the sales function. As in the uniform case, the $V_{\text {warranty }}(t)$ curves are delayed with with respect to the one corresponding to Case 1 (all elements sold at $\mathrm{t}=0$ ). For example, in the case of having a mean of 10 years in the normal distribution, the last element sold will be at $L=20$ years. Therefore, the last item covered by the warranty will be at 45 years $(L+W)$ in Figure 10 . 


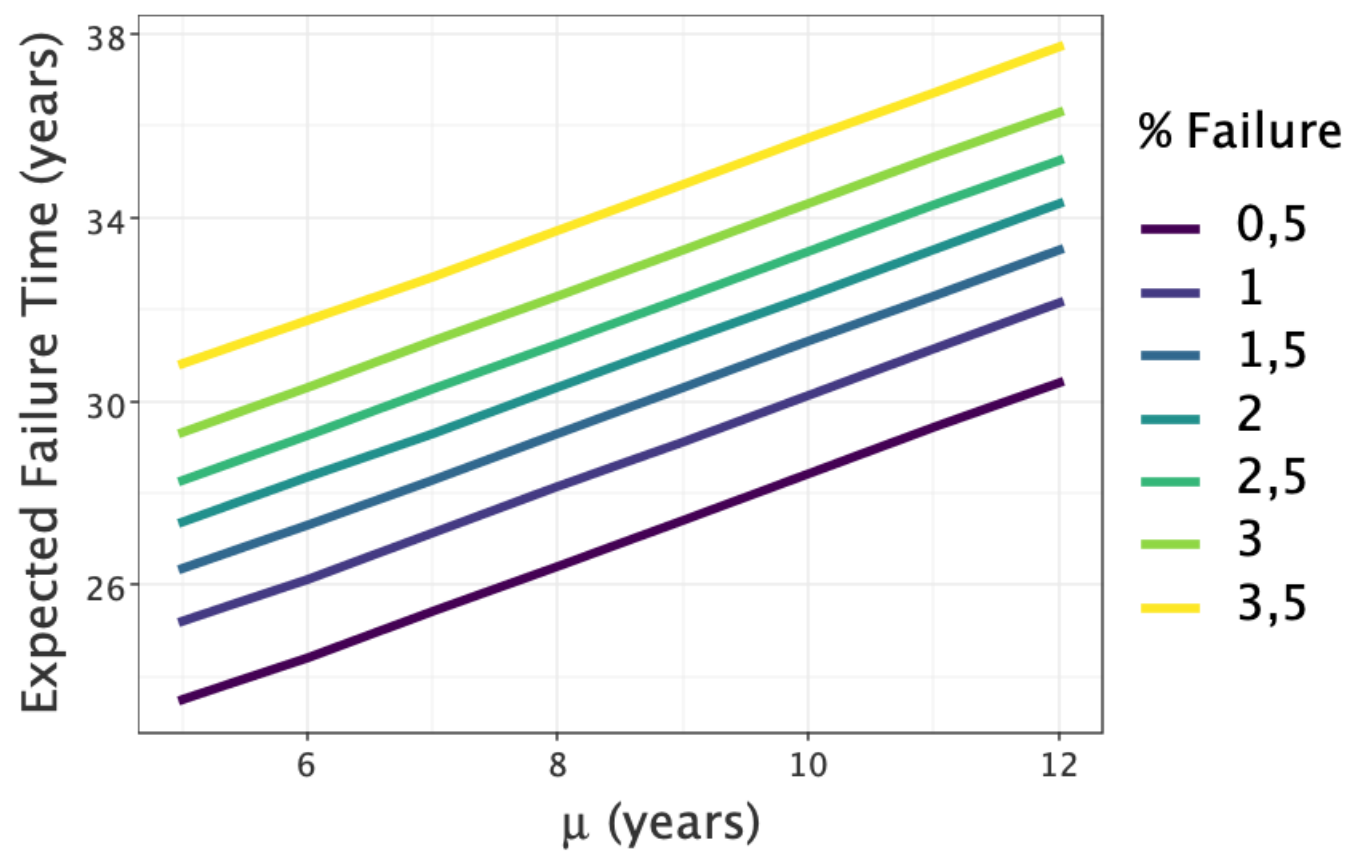

Figure 11: Expected failure time vs normal sales distribution for different percentage of failed elements covered by warranty.

As in the uniform case, we have represented the expected failure time with respect to the normal mean of the sales distribution for different percentage of failures covered by the warranty (Figure 11). This figure allows the practitioner to quickly estimate the required spares for a proper maintenance. Note that, although the exact values obtained depend on the specific degradation and sales parameters, our model can be applied for any particular situation.

\subsection{INFLUENCE OF DEGRADATION IN THE WARRANTY ANALYSIS}

In this section we discuss some common issues affecting degradation and, in turn, the proportion of PV modules returned during the warranty:

- Influence of the PV location. This is a very important factor, as reported in [12,14,28]. A good review of the main failure mechanisms affecting the PV modules depending on climatic environment can be found in [14]. It has been observed that locations with the higher irradiance are not always the most cost-effective for PV applications due to reliability reasons [29]. In the literature there is an interesting work that analyses the degradation of PV power for the different climates of Köppen-Geiger climate [12]: A (tropical), B (dry), C (temperate), D (continental), and E (polar). In high-temperature climates, PV plants show more evident degradation mechanisms (1,13\%/year). Moderate performance losses can be founded in continental $(0,58 \%$ year) and desert climates $(0,75 \% /$ year $)$. The tropical climate supports the lowest degradation/rate of $0.33 \% / y e a r$, which is the case for the investigated system in this paper. Based on these degradation rate data, it will only be possible to offer 25 years warranty in the climates with lowest degradation rate (tropical and continental) and it will not be possible in temperate and 
desert climates. As temperature is a key factor in degradation processes [29] it will be reasonable to assume that the degradation rate in the polar climate will be in the lower range and it will be possible to meet the warranty periods.

- Influence of non-linearities in the degradation rate. Some works address non-linear trends, which mostly occur at the beginning of product's life or during the wear-out phase [11]. Depending on the degradation mechanism, non-linearity can be convex or concave in time, and when several mechanisms occur, non-linearities affect them in different ways. It is possible to include variable degradation rates in our model and this effect will be analyzed in a future work. But as a first conclusion we see that, if the degradation rate increases over time, failures will increase and appear earlier. On the other hand, if the rate of degradation decreases over time, failures will decrease and appear later.

- Skewness of the distribution. Previous work has shown that in many cases the distribution of energy does not follow a normal distribution because the distribution is not symmetrical but skewed [30]. This asymmetry is usually left-skewed and increases over time. This means that there are some robust photovoltaic modules that decrease their power very slowly, but there are also others that decrease much faster. As these PV modules that degrade at a higher rate can be a significant proportion of the total, this asymmetry can anticipate the occurrence of failures within the warranty period.

- Difficulties in claiming warranty degradation failures. Manufacturers of PV modules have been offering 25 -year warranty since the late 1990s. This long warranty period is supported by the low number of PV modules returned for warranty claim. However, according to the model described in this document, there will be a significant percentage of failed modules unclaimed due to some difficulties in the claim process:

- $\quad$ The power of each PV module must be characterized by a recognized testing company, taking into account both manufacturing and measurement tolerances.

- $\quad$ A PV module is usually embedded into a PV system, and the power degradation of the whole system can be due to several factors, such as the DC/AC inverter, conductors etc.

- Depending on how the PVs are arranged in a PV system (e.g. serial-parallel) the degradation of a module can be shadowed by the performance of the rest of modules. However, depending on how the module is electrically connected and the type of degradation $\left(I_{s c}\right.$ or $\left.V_{o c}\right)$, degradation of a single module can significantly affect the entire PV system due to mismatch losses [27]. Evaluating the performance of a specific PV module in an array system is not an easy task.

All these difficulties are relevant in the new scenario of large AC grid-connected systems with favorable feed-in tariffs. In this new scenario it is very difficult to identify PV modules that fail due to degradation. Based on this, the addition of warranty models based on degradation is a key tool to quantify failures in the warranty time. 


\section{SUMMARY AND CONCLUSIONS}

In PV systems, the cost of the modules is a key component of the entire budget. Therefore, their reliability and degradation are a major concern. In order to be competitive, PV modules need to be maintained for 25 to 30 years and, due to the high reliability of PV modules, manufacturers offer very extensive warranties (e.g. 25 years).

In addition, PV modules produce a very small number of returns within the warranty period [6], with the exception of catastrophic failures due to difficulties in measuring the power of an individual module. However, it has recently been highlighted [20], that the main reliability problem of PV modules is not related to catastrophic failures but to the degradation of PV power. Furthermore, although all PV module manufacturers offer these long warranty periods, the degradation rates reported in the literature are very varied. It will be very interesting for manufacturers and users to estimate whether PV modules comply with the warranty based on experimental degradation data.

This document has focused on obtaining a quantitative relationship between the parameters of power degradation of the photovoltaic modules and the fulfilment of the guaranteed power. A probabilistic model allowed us to understand which parameters are relevant in the warranty of the PV modules and to estimate the associated costs. The model was applied to PV module field degradation data obtaining the following results:

- The percentage of PV modules that fail during the warranty period depends only on the degradation parameters and not on the sales function.

- Assuming an upper threshold of $5 \%$ of the returned modules and if the mean degradation rate is equal or higher than $0,73 \%$ year, $\frac{A}{P_{0}}>0,73 \% /$ year, it is not possible to fulfill 25 years of warranty. Note that this value is evaluated assuming that the standard deviation at $t=0$ is 0,01 and that there is no increase in standard deviation during degradation according to our model.

- If the standard deviation of the power distribution increases over time and we use the reference value $\frac{B}{P_{0}}=0,215 \% /$ year $[18,26]$, the mean degradation rate must not exceed $0,38 \% /$ year, $\frac{A}{P_{0}} \leq 0,38 \% /$ year, to comply with a 25 -year warranty with a maximum of $5 \%$ of the returned modules.

- If we compare the required degradation rates with experimental data in field 25 years warranties are achieves in benign climates but not in the most aggressive:

o From [13], the median degradation rate of $S i$ modules varies from $0,35 \% /$ year up to $0,71 \% /$ year depending on the environment.

o From [12] the degradation rates are in a wide range depending the climate, from $0,33 \% /$ year up to $1,13 \%$ /year. 
- Once it has been assessed the percentage of photovoltaic modules that fail in warranty it is very important from logistic point of view to know when the modules fail covered by warranty. Although this depends both on the failures $f(t)$ obtained from degradation parameters, and on the sales distributions $s(t)$, it is possible to obtain the following conclusions:

- $\quad$ There is no significant number of degradation failures during the first 10 years of the PV module's life and this must be considered in the replacement logistics. After that period, possible warranty claims will increase considerably. The exact time at which failures increase and the associated failure rate depends on both the specific degradation parameters and the sales function.

- $\quad$ The time distribution of failures covered by the warranty is affected by the sales function, $s(t)$, delaying the distribution with respect to whether all items are sold at $t=0$. An analysis considering the uniform sales distribution and the normal sales distribution with different parameters has been shown in Section 4 (Figures 7-11).

- Although the results evaluating the distribution of failures covered by the warranty (which are very important for logistical purposes) focus on specific case studies, our warranty model can be applied to any real case. Replacement logistics can be designed based on a specific analysis of the actual system, the degradation parameters and the sales function.

- The warranty model is based on a constant degradation rate and normal power distribution at each instant of time. It has been observed in the literature that there are photovoltaic modules that degrade at a non-constant degradation rate [11] and with asymmetrical power distributions [30]. Considering these effects in the warranty model is possible and it will be taken into account in future work.

\section{ACKNOWLEDGEMENTS}

This paper has been supported by the Comunidad de Madrid through the project MADRIDPV2(S2018/EMT-4308) and Universidad Politécnica de Madrid by means of the project RP150910B12 


\section{REFERENCES}

[1] Wohlgemuth, J. H. (2020). Photovoltaic Module Reliability. John Wiley \& Sons.

[2] Shimura, S., Herrero, R., Zuffo, M. K., \& Grimoni, J. A. B. (2016). Production costs estimation in photovoltaic power plants using reliability. Solar Energy, 133, 294-304.

[3] Jordan, D. C., Marion, B., Deline, C., Barnes, T., \& Bolinger, M. PV field reliability status—Analysis of 100000 solar systems. Progress in Photovoltaics: Research and Applications https://doi.org/10.1002/pip.3262, 2020.

[4] Peters, L., \& Madlener, R. (2017). Economic evaluation of maintenance strategies for groundmounted solar photovoltaic plants. Applied Energy, 199, 264-280.

[5] His, E. P., \& Shieh, J. C. (2019, June). Insurability of PV Performance Liability and its Impact on Overall PV Financing Costs. In 2019 IEEE 46th Photovoltaic Specialists Conference (PVSC) (pp. 1653-1655).

[6] Wohlgemuth, J. H., Cunningham, D. W., Monus, P., Miller, J., \& Nguyen, A. (2006, May). Long term reliability of photovoltaic modules. In 2006 IEEE 4th World Conference on Photovoltaic Energy Conference (Vol. 2, pp. 2050-2053).

[7] Rajput, P., Malvoni, M., Kumar, N. M., Sastry, O. S., \& Tiwari, G. N. (2019). Risk priority number for understanding the severity of photovoltaic failure modes and their impacts on performance degradation. Case Studies in Thermal Engineering, 16, 100563.

[8] Skoczek, A., Sample, T., \& Dunlop, E. D. (2009). The results of performance measurements of field-aged crystalline silicon photovoltaic modules. Progress in Photovoltaics: Research and applications, 17(4), 227-240.

[9] Chandel, S. S., Naik, M. N., Sharma, V., \& Chandel, R. (2015). Degradation analysis of 28 year field exposed mono-c-Si photovoltaic modules of a direct coupled solar water pumping system in western Himalayan region of India. Renewable Energy, 78, 193-202.

[10] Ishii, T., \& Masuda, A. (2017). Annual degradation rates of recent crystalline silicon photovoltaic modules. Progress in Photovoltaics: Research and Applications, 25(12), 953-967.

[11] Jordan, D. C., Silverman, T. J., Sekulic, B., \& Kurtz, S. R. (2017). PV degradation curves: nonlinearities and failure modes. Progress in Photovoltaics: Research and Applications, 25(7), 583591.

[12] Malvoni, M., Kumar, N. M., Chopra, S. S., \& Hatziargyriou, N. (2020). Performance and degradation assessment of large-scale grid-connected solar photovoltaic power plant in tropical semiarid environment of India. Solar Energy, 203, 101-113.

[13] Jordan, D. C., Kurtz, S. R., VanSant, K., \& Newmiller, J. (2016). Compendium of photovoltaic degradation rates. Progress in Photovoltaics: Research and Applications, 24(7), 978-989.

[14] Omazic, A., Oreski, G., Halwachs, M., Eder, G. C., Hirschl, C., Neumaier, L., ... \& Erceg, M. (2019). Relation between degradation of polymeric components in crystalline silicon PV module and climatic conditions: A literature review. Solar Energy Materials and Solar Cells, 192, 123133.

[15] Lyu, Y., Fairbrother, A., Gong, M., Kim, J. H., Gu, X., Kempe, M., .. \& O'Brien, G. (2020). Impact of environmental variables on the degradation of photovoltaic components and perspectives for the reliability assessment methodology. Solar Energy, 199, 425-436.

[16] Murthy, D. N. P., \& Djamaludin, I. (2002). New product warranty: A literature review. International Journal of Production Economics, 79(3), 231-260.

[17] Murthy, D. P., \& Blischke, W. R. (2006). Warranty management and product manufacture. Springer Science \& Business Media.

[18] Murthy, D. N. P. (2006). Product warranty and reliability. Annals of Operations Research, 143(1), 133-146.

[19] Yang, G. (2007). Life cycle reliability engineering. John Wiley \& Sons.

[20] Vázquez, M., \& Rey-Stolle, I. (2008). Photovoltaic module reliability model based on field degradation studies. Progress in photovoltaics: Research and Applications, 16(5), 419-433.

[21] Model, Product Life Cycle Data. "American Standard ANSI." EIA-724, Sept 19 (1997). 
[22] Sandborn, P. A., Mauro, F., \& Knox, R. (2007). A data mining based approach to electronic part obsolescence forecasting. IEEE Transactions on Components and Packaging Technologies, 30(3), 397-401.

[23] González, J. R., Vázquez, M., Algora, C., \& Núñez, N. (2011). Real-time reliability test for a CPV module based on a power degradation model. Progress in Photovoltaics: Research and Applications, 19(1), 113-122.

[24] Osterwald, C. R., Adelstein, J., Del Cueto, J. A., Kroposki, B., Trudell, D., \& Moriarty, T. (2006, May). Comparison of degradation rates of individual modules held at maximum power. In 2006 IEEE 4th World Conference on Photovoltaic Energy Conference (Vol. 2, pp. 2085-2088).

[25] Hocine, L., \& Samira, K. M. (2019). Optimal PV panel's end-life assessment based on the supervision of their own aging evolution and waste management forecasting. Solar Energy, 191, 227-234.

[26] Chamberlin, C. E., Rocheleau, M. A., Marshall, M. W., Reis, A. M., Coleman, N. T., \& Lehman, P. A. (2011, June). Comparison of PV module performance before and after 11 and 20 years of field exposure. In 2011 37th IEEE Photovoltaic Specialists Conference (pp. 000101-000105).

[27] Han, C., \& Lee, H. (2018). Investigation and modeling of long-term mismatch loss of photovoltaic array. Renewable energy, 121, 521-527.

[28] Kahoul, N., Houabes, M., \& Sadok, M. (2014). Assessing the early degradation of photovoltaic modules performance in the Saharan region. Energy conversion and management, 82, 320326.

[29] Vazquez, M., Tamayo-Arriola, J., Orlando, V., Nuñez, N., Alburquerque, O., \& Algora, C. (2017). Reliability of commercial triple junction concentrator solar cells under real climatic conditions and its influence on electricity cost. Progress in Photovoltaics: Research and Applications, 25(11), 905-918

[30] Jordan, D. C., Wohlgemuth, J. H., \& Kurtz, S. R. (2012). Technology and climate trends in PV module degradation 27th European Photovoltaic Solar Energy, Frankfurt- Germany, 2012. 